\title{
UJI EFEK ANTIBAKTERI EKSTRAK DAUN TEH (Camellia sinensis L.) TERHADAP PERTUMBUHAN BAKTERI Escherichia coli
}

\author{
Amriani, Lanny Permata Sari \\ Jurusan Farmasi Poltekkes Kemenkes Medan
}

\begin{abstract}
Abstrak
Indonesia merupakan salah satu negara yang banyak ditumbuhi beraneka ragam tanaman yang berpotensi sebagai tanaman obat tradisional. Salah satu tanaman yang dapat berguna sebagai obat adalah tanaman teh (Camellia sinensis L.).Tanaman teh mengandung katekin yang berkhasiat sebagai antibakteri dan antidiare. Tujuan penelitian ini untuk melihat efek antibakteri ekstrak daun teh terhadap pertumbuhan bakteri Escherichia coli dan untuk mengetahui konsentrasi ekstrak daun teh yang dapat menghambat pertumbuhan bakteri Escherichia coli. Bakteri adalah sel prokariotik dan uniselular. Bakteri Escherichia coli merupakan salah satu bakteri gram negatif dan dapat menyebabkan penyakit infeksi saluran kemih dan diare. Ekstrak daun teh dibuat secara perkolasi dengan menggunakan etanol $96 \%$ sebagai cairan penyari yang kemudian diuapkan dengan rotavapor. Uji aktivitas antibakteri dilakukan menggunakan metode difusi yaitu menggunakan media agar yang telah ditanami bakteri, kemudian dibuat 6 hole. Lima hole ditetesi larutan uji yaitu ekstrak daun teh 2\%, 3\%, 4\%, 5\%, 6\% dan satu hole ditetesi kontrol negatif yaitu alkohol $96 \%$. Menurut Farmakope Indonesia Edisi IV, zona hambatan antibakteri yang memuaskan adalah 14-16 mm. Dari data hasil pengamatan dapat dilihat bahwa ekstrak daun teh $2 \%$ belum dapat dikatakan sebagai antibakteri, tetapi sudah dapat menghambat pertumbuhan bakteri. Ekstrak daun teh 3\%, 4\%, 5\% dan 6\% telah dapat dikatakan sebagai antibakteri dengan masing-masing diameter zona hambatnya 14,1 mm; 14,9 $\mathrm{mm} ; 15,1 \mathrm{~mm} ; 15,8 \mathrm{~mm}$. Ekstrak daun teh 3\% merupakan konsentrasi hambat minimum dalam menghambat pertumbuhan bakteri Escherichia coli. Kontrol negatif yaitu etanol $96 \%$ ternyata tidak memiliki efek antibakteri.
\end{abstract}

Kata Kunci : Daun teh, Antibakteri, Escherichia coli

\section{PENDAHULUAN}

Indonesia merupakan salah satu negara yang banyak ditumbuhi beraneka ragam tanaman yang berpotensi sebagai tanaman obat tradisional. Sejak dahulu masyarakat Indonesia telah memanfaatkan tanaman obat tersebut sebagai salah satu upaya untuk mengobati penyakit. Pemanfaatan tanaman obat merupakan warisan budaya nenek moyang yang diwariskan secara turun temurun hingga ke generasi sekarang berdasarkan pengetahuan dan pengalaman.

Diantara keanekaragaman tanaman, salah satu yang dapat berguna sebagai obat adalah tanaman teh (Camellia sinensis L.). Bagian tanaman teh yang digunakan sebagai obat adalah daunnya. Daun teh mengandung beberapa zat-zat antara lain polifenol 30$40 \%$, kafein, minyak atsiri dan tanin. Polifenol daun teh yang terkenal adalah katekin (Trubus vol. 10). Katekin memiliki khasiat sebagai antibakteri (Rossi, 2010). Selain itu juga berkhasiat sebagai antidiare (The Merck Index, 2006).

Daun teh berguna untuk mengatasi sakit kepala, penyubur dan menghitamkan rambut, diabetes mellitus, mengurangi terbentuknya karang gigi, infeksi saluran cerna dan diare (Dalimartha, 1999). Pada masyarakat pedesaan yang tinggal di daerah perkebunan, daun teh biasa digunakan dalam usaha pertolongan awal pada penderita diare (Department of Food Science and Technology, 2010). Di daerah Jawa orang yang menderita diare juga biasanya diberikan air teh panas (Werner, dkk., 2010). Di Cina, teh juga digunakan untuk mengobati penyakit disentri dan diare (Heinrich, et.al, 2009).

Salah satu penyebab penyakit diare dikarenakan infeksi bakteri Escherichia coli. Bakteri Escherichia coli merupakan salah satu bakteri gram negatif. Bakteri ini umumnya ditemukan dalam usus besar manusia dan dapat juga menyebabkan penyakit lain seperti pneumonia, meningitis dan infeksi saluran kemih. Berdasarkan uraian tersebut, maka penulis tertarik untuk meneliti "Uji Efek Antibakteri Ekstrak Daun Teh (Camellia sinensis L.) terhadap Pertumbuhan Bakteri Escherichia coli",.

Adapun tujuan penelitian ini untuk melihat efek antibakteri ekstrak daun teh terhadap pertumbuhan bakteri Escherichia coli dan untuk mengetahui pada konsentrasi berapa ekstrak daun teh (Camellia sinensis L.) tersebut dapat menghambat pertumbuhan bakteri Escherichia coli.

Selain itu juga penelitian ini dapat memberikan informasi kepada masyarakat bahwa daun teh dapat dijadikan sebagai penyembuhan penyakit 
yang disebabkan oleh bakteri Escherichia coli dan bagi akademis, gagasan ini dapat mendorong dan mengkaji lebih lanjut untuk memformulasi sediaan yang dibuat dari daun teh yang dapat digunakan dalam penyembuhan penyakit yang disebabkan oleh bakteri Escherichia coli.

\section{METODOLOGI PENELITIAN}

\section{Metode Penelitian}

Penelitian ini dilakukan dengan menggunakan metode eksperimental secara uji mikrobiologi di Laboratorium Mikrobiologi Jurusan Farmasi Poltekkes Kemenkes Medan.

\section{Pengambilan Sampel}

Pada penelitian ini sampel yang digunakan adalah daun teh varietas assamica yang masih muda yang tumbuh di daerah Perkebunan Sidamanik Kabupaten Simalungun. Pengambilan sampel dilakukan secara purposive yaitu sampel yang dipilih secara khusus berdasarkan tujuan penelitian tanpa membandingkan dengan tumbuhan yang sama dari tempat lain.

\section{Alat dan Bahan}

Alat-alat yang di gunakan dalam penelitian ini adalah : Autoklaf, batang pengaduk, beaker glass, botol berwarna gelap, cawan petri, erlenmeyer , gelas ukur, Incubator, jangka sorong, kain flannel, kapas, kawat ose, kertas

perkamen,kertassaring,labutentukur,lampuspiritus,mikrosk op,oven,percolator, plastikdanKaret, rak tabung reaksi, ring percolator, spidol, statip, mat pipet $5 \mathrm{ml}$, tabung reaksi,tali atau benang.

Bahan- bahan yang digunakan dalam penelitian ini : Daun Teh (Camellia sinensis L.), Etanol 96\%, Eosin Methylen Blue Agar (EMBA), Media Mueller Hinton Agar (MHA), Nutrient Agar, Bakteri Escherichia coli, Larutan Kristal violet, Larutan Lugol, Larutan Fuchsin, Suspensi Mc. Farland dan Aquadest.

\section{Pengolahan Sampel}

Daun teh yang masih segar dibersihkan dari kotoran-kotoran yang menempel dengan air bersih, lalu ditiriskan. Iris daun teh dengan lebar $0,3 \mathrm{~cm}(3 \mathrm{~mm})$. Keringkan pada suhu kamar, terlindung dari sinar matahari langsung kemudian daun yang sudah kering dihaluskan hingga menjadi serbuk.

\section{Perhitungan Pembuatan Ekstrak Daun The}

Pada penelitian ini, ekstrak dibuat dengan cara perkolasi dengan menggunakan cairan penyari etanol $96 \%$.

$>100$ bagian ekstrak cair yang akan dibuat $=2500$ gram

Maka 10 bagian serbuk daun teh $=250$ gram

$>$ Menurut Farmakope Indonesia edisi IV, Bj alkohol $=0,812-0,816$

Maka Bj rata-ratanya $=\frac{0,812+0,816}{2}=0,814$

$>$ Volume 100 bagian ekstrak cair :

$$
\begin{aligned}
\mathrm{v} & =\frac{\mathrm{m}}{b j} \\
\mathrm{v} & =\frac{2500 \mathrm{~g}}{0,814 \mathrm{~g} / \mathrm{ml}}=3071 \mathrm{ml}
\end{aligned}
$$

$>5$ bagian cairan penyari untuk membasahi serbuk daun teh:

$$
\frac{5}{100} \times 3071 \mathrm{ml}=153,55 \mathrm{ml}=153,6 \mathrm{ml}
$$

\section{Pembuatan Ekstrak Daun Teh}

Sepuluh (10) bagian (250 gram) serbuk daun the ditimbang lalu dimasukkan ke dalam wadah. Kemudian ditambahkan 5 bagian $(153,6 \mathrm{ml})$ cairan penyari yaitu etanol $96 \%$, diaduk hingga semua permukaan serbuk daun teh basah dan diamkan selama 3 jam. Serbuk daun teh dipindahkan sedikit demi sedikit ke dalam perkolator sambil ditekan hati-hati dengan menggunakan batang pengaduk. Etanol 96\% dimasukkan ke dalam perkolator secara perlahan-lahan sehingga terdapat selapis cairan penyari di atas serbuk daun teh yang berada dalam perkolator. Perkolator ditutup dengan menggunakan plastik, lalu didiamkan selama 24 jam. Pipet kapiler dibuka dan dibiarkan cairan penyari (etanol 96\%) menetes dengan kecepatan $1 \mathrm{ml} /$ menit. Etanol 96\% ditambahkan ke dalam perkolator hingga selalu terdapat selapis cairan penyari di atas serbuk daun teh. Perkolat ditampung hingga warna perkolat yang keluar terakhir tidak berwarna lagi. Akhirnya Perkolat diuapkan dengan rotavapor pada suhu tidak lebih dari $50^{\circ} \mathrm{C}$ hingga diperoleh ekstrak kental. Ekstrak kental yang diperoleh adalah 29,22 gram.

\section{Perhitungan Konsentrasi Ekstrak Daun Teh}

Daun teh yang digunakan untuk obat diare secara empiris dilakukan dengan cara merebus daun teh yang masih muda dan segar sebanyak $20 \mathrm{~g}$ dengan 3 gelas air, sehingga diperoleh konsentrasinya:

1 gelas air $=200 \mathrm{ml}$

3 gelas air $=600 \mathrm{ml}$

$$
\checkmark \quad \frac{20 \mathrm{~g}}{600 \mathrm{ml}} \times 100 \%=3,33 \%
$$

Kosentrasi daun teh yang dibuat secara empiris adalah 3,33\%, maka pada penelitian ini peneliti mengambil konsentrasi di bawah dan di atas konsentrasi 3,33\% yaitu $2 \%, 3 \%, 4 \%, 5 \%, 6 \%$

$\checkmark \quad$ Untuk membuat ekstrak daun teh konsentrasi 6\%:

$6 \%=6 \mathrm{~g} / 100 \mathrm{ml}$

Maka untuk membuat $50 \mathrm{ml}$ :

$$
\frac{50 \mathrm{ml}}{100 \mathrm{ml}} \times 6 \mathrm{~g}=3 \mathrm{~g}
$$

Ekstrak kental daun teh ditimbang sebanyak $3 \mathrm{~g}$ kemudian dicukupkan dengan etanol $96 \%$ hingga 50 $\mathrm{ml}$.

$\checkmark$ Untuk membuat $6 \mathrm{ml}$ ekstrak daun teh $5 \%$, dibuat dengan pengenceran ekstrak daun teh $6 \%$, yaitu:

$\mathrm{V}_{1} \cdot \mathrm{N}_{1}=\mathrm{V}_{2} \cdot \mathrm{N}_{2}$

$\mathrm{V}_{1 .} .6 \%=6.5 \%$

$\mathrm{V}_{1}=5 \mathrm{ml}$. Maka pipet $5 \mathrm{ml}$ ekstrak daun teh $6 \%$, tambahkan etanol $96 \%$ sampai $6 \mathrm{ml}$

$\checkmark$ Untuk membuat $6 \mathrm{ml}$ ekstrak daun teh $4 \%$, dibuat dengan pengenceran ekstrak daun teh $6 \%$, yaitu: 
$\mathrm{V}_{1} \cdot \mathrm{N}_{1}=\mathrm{V}_{2} \cdot \mathrm{N}_{2}$

$\mathrm{V}_{1 .} .6 \%=6.4 \%$

$\mathrm{V}_{1}=4 \mathrm{ml}$. Maka pipet $4 \mathrm{ml}$ ekstrak daun teh $6 \%$, tambahkan etanol $96 \%$ sampai $6 \mathrm{ml}$

$\checkmark$ Untuk membuat $6 \mathrm{ml}$ ekstrak daun teh $3 \%$, dibuat dengan pengenceran ekstrak daun teh $6 \%$, yaitu:

$\mathrm{V}_{1} \cdot \mathrm{N}_{1}=\mathrm{V}_{2} \cdot \mathrm{N}_{2}$

$\mathrm{V}_{1 .} .6 \%=6.3 \%$

$\mathrm{V}_{1}=3 \mathrm{ml}$. Maka pipet $3 \mathrm{ml}$ ekstrak daun teh $6 \%$, tambahkan etanol $96 \%$ sampai $6 \mathrm{ml}$

$\checkmark$ Untuk membuat $6 \mathrm{ml}$ ekstrak daun teh $2 \%$, dibuat dengan pengenceran ekstrak daun teh $6 \%$, yaitu:

$\mathrm{V}_{1} \cdot \mathrm{N}_{1}=\mathrm{V}_{2} \cdot \mathrm{N}_{2}$

$\mathrm{V}_{1 .} .6 \%=6.2 \%$

$\mathrm{V}_{1}=2 \mathrm{ml}$. Maka pipet $2 \mathrm{ml}$ ekstrak daun teh $6 \%$, tambahkan etanol $96 \%$ sampai $6 \mathrm{ml}$

\section{Prosedur Kerja}

Pembuatan Media Eosine Methylen Blue Agar (EMBA)

Jumlah media yang harus dilarutkan dalam 1 liter aquadest pada etiket adalah $36 \mathrm{~g} / \mathrm{l}$. Banyaknya EMBA yang diperlukan untuk $50 \mathrm{ml}$ adalah:

$$
\frac{50 \mathrm{ml}}{1000 \mathrm{ml}} \times 36 \mathrm{~g}=1,8 \mathrm{~g}
$$

Pembuatan:

EMBA ditimbang sebanyak 1,8 gram, kemudian dimasukkan ke dalam erlenmeye dan dilarutkan dengan aquadest sebanyak $50 \mathrm{ml}$ lalu dianaskan sampai mendidih. Setelah mendidih diangkat dan erlenmeyer ditutup dengan kapas dan dilapisi dengan kertas perkamen, kemudian ikat dengan benang. Sterilkan dalam autoklaf pada suhu $121^{\circ} \mathrm{C}$ selama 15 menit, setelah steril, diangkat dari autoklaf dengan perlahanlahan dan hati-hati. Dinginkan sejenak, kertas perkamen yang diikatkan pada Erlenmeyer dibuka kemudian dituang ke dalam cawan petri secara aseptis dan dibiarkan agar dingin dan memadat.

\section{Pembuatan Media Mueller Hilton Agar (MHA)}

Jumlah media yang dilarutkan dalam 1 liter aquadest pada etiket adalah $34 \mathrm{~g} / \mathrm{l}$. Banyaknya MHA yang diperlukan $100 \mathrm{ml}$ adalah:

$$
\frac{100 \mathrm{ml}}{1000 \mathrm{ml}} \times 34 \mathrm{~g}=3,4 \mathrm{~g}
$$

\section{Pembuatan:}

MHA ditimbang sebanyak 3,4 gram dan dimasukkan ke dalam erlenmeyer, lalu dilarutkan dengan aquadest sebanyak $100 \mathrm{ml}$, kemudian dipanaskan sampai mendidih, diangkat dan erlenmeyer ditutup dengan kapas, lalu dilapisi dengan kertas perkamen, kemudian ikat dengan benang.Kemudian sterilkan dalam autoklaf pada suhu $121^{\circ} \mathrm{C}$ selama 15 menit

\section{Pembuatan Media Nutrien Agar (NA)}

Jumlah media yang harus dilarutkan dalam 1 liter aquadest pada etiket adalah $20 \mathrm{~g} / \mathrm{L}$. Banyaknya Nutrien Agar yang dibutuhkan untuk $20 \mathrm{ml}$ adalah:

$$
\frac{20 m l}{1000 m l} \times 20 \mathrm{~g}=0,4 \mathrm{~g}
$$

Pembuatan:

Nutrien Agar ditimbang sebanyak 0,4 g, lalu dimasukkan kedalam erlenmeyer, larutkan dengan aquadest sebanyak $20 \mathrm{ml}$ serta dipanaskan sampai mendidih. Setelah mendidih diangkat, lalu dibagi dalam beberapa tabung (sesuai kebutuhan), ditutup dengan kapas, dilapisi dengan kertas perkamen kemudian diikat dengan benang dan disterilkan dalam autoklaf pada suhu $121^{\circ} \mathrm{C}$ selama 15 menit. Setelah steril, angkat dari autoklaf dengan perlahan-lahan dan hatihati. Setelah disterilkan kemudian dinginkan, kertas perkamen yang diikatkan pada tabung dibuka kemudian tabung yang berisi Nutiren Agar dimiringkan untuk memperoleh agar miring dan dibiarkan sampai membeku, setelah itu dilakukan penanaman bakteri dengan menggoreskan bakteri secara zig-zag pada media.

\section{Larutan $\mathrm{NaCl} 0,9 \%$}

Larutan ini digunakan untuk mensuspensikan bakteri dan pengenceran bakteri.

Pembuatan:

$\mathrm{NaCl}$ ditimbang sebanyak 0,9 g lalu dilarutkan dengan aquadest hingga $100 \mathrm{ml}$ dalam labu tentukur, kemudian disterilkan dalam autoklaf pada suhu $121^{\circ} \mathrm{C}$ selama 15 menit.

\section{Suspensi Standar Mc. Farland}

Pembuatan:

Larutan Asam Sulfat dicampur dengan Larutan Barium Klorida didalam tabung reaksi dan dikocok homogen. Apabila kekeruhan suspensi bakteri uji sama dengan kekeruhan suspensi standar Mc. Farland, maka konsentrasi suspensi bakteri adalah $10^{8} \mathrm{koloni} / \mathrm{ml}$.

\section{Pembiakan Bakteri}

Ambil satu ose dari suspensi bakteri Escherichia coli, kemudian ditanam ke media EMBA dengan cara menggoreskan, Inkubasi dalam inkubator pada suhu $37^{\circ} \mathrm{C}$ selama 24 jam lalu diamati pertumbuhan koloni pada media. Hasil yang diperoleh koloni berwarna hijau dengan kilap logam dan bintik biru kehijauaan ditengahnya menunjukkan Escherichia coli (+), lalu dilakukan pengecatan gram dengan cara:

- Ambil biakan bakteri yang telah berumur 24 jam, letakkan pada kaca objek yang telah diberikan aquadest lebih dahulu, lalu fiksasi 
- Tambahkan kristal violet, diamkan 1 menit, kemudian bilas dengan aquadest dan tambahkan larutan lugol, biarkan selama 1 menit

- Setelah 1 menit lugol dibilas dengan aquadest, kemudian tuangi dengan alkohol $96 \%$ setetes demi setetes hingga warna Kristal violet hilang, kemudian bilas kembali dengan aquadest

- Tambahkan larutan Fuchsin diamkan kira-kira 20 detik, bilas dengan aquadest lalu keringkan dengan kertas hisap secara hati-hati

- Amati hasilnya di bawah mikroskop dengan perbesaran 10X40 dan 10X100

- Jika bakteri tersebut adalah Escherichia coli hasil yang diperoleh di bawah mikroskop adalah bakteri berwarna merah yang merupakan bakteri gram negatif berbentuk batang

- Lalu koloni spesifik Escherichia coli diambil satu ose lalu ditanamkan pada Nutrien Agar miring, inkubasi dalam inkubator pada suhu $37^{\circ} \mathrm{C}$ selama 24 jam

\section{Pengenceraan Bakteri Escherichia coli}

1 ml larutan $\mathrm{NaCl}$ 0,9\% dimasukkan kedalam tabung kosong, kemudian ditambahkan satu ose biakan bakteri Escherichia coli yang berumur 18-24 jam yaitu biakan yang berasal dari Nutrien Agar. Kemudian tambahkan terus larutan $\mathrm{NaCl}$ 0,9\% sampai diperoleh suspensi dengan kekeruhan yang sama dengan suspensi standar Mc. Farland, maka konsentrasi suspensi bakteri adalah $10^{8} \mathrm{koloni} / \mathrm{ml}$. Suspensi bakteri dimasukkan dengan menggunakan pipet sebanyak $0,1 \mathrm{ml}$ kedalam tabung reaksi kemudian tambahkan 9,9 ml larutan $\mathrm{NaCl} 0,9 \%$, sehingga konsentrasi suspensi bakteri adalah $10^{6}$ koloni/ml.

\section{Uji Efek Antibakteri Ekstrak Daun Teh terhadap} Pertumbuhan Bakteri Escherichia coli

1. Sterilkan semua alat dan bahan yang akan digunakan.

2. Buat persediaan inokulum.

3. Pipet $0,1 \mathrm{ml}$ suspensi bakteri dengan konsentrasi $10^{6}$ koloni/ ml ke dalam $100 \mathrm{ml}$ media MHA dengan suhu $45^{\circ}-50^{\circ} \mathrm{C}$ lalu kocok sampai homogen, kemudian tuang segera sebanyak $15 \mathrm{ml}$ kedalam cawan petri steril, lalu biarkan memadat.

4. Buat 6 hole, 5 hole untuk ekstrak daun teh, 1 hole untuk etanol 96\% sebagai kontrol negatif.

5. Tetesi masing-masing ke dalam hole $0,1 \mathrm{ml}$ ekstrak daun teh dengan konsentrasi $2 \%, 3 \%, 4 \%$, $5 \%, 6 \%$ dan pada 1 hole $0,1 \mathrm{ml}$ etanol $96 \%$

6. Kemudian cawan petri diinkubasikan selama 24 jam pada suhu $37^{0} \mathrm{C}$.

7. Kemudiaan dilihat dan diukur zona hambatan berupa daerah yang tampak jernih yang tidak ditumbuhi oleh bakteri Escherichia coli

8. Percobaan dilakukan triplo yaitu dilakukan sebanyak 3 kali untuk masing-masing ekstrak daun teh.

\section{HASIL DAN PEMBAHASAN}

Pengukuran hasil penelitian dilakukan dengan mengukur zona hambatan ekstrak kental daun teh dengan konsentrasi 2\%, 3\%, 4\%, 5\%, 6\% terhadap pertumbuhan bakteri Escherichia coli dimana terlihat daerah jernih disekitar lubang difusi (hole), seperti yang terlihat pada tabel berikut ini:

Tabel. Hasil pengamatan zona hambatan ekstrak daun teh terhadap pertumbuhan Escherichia coli dengan satuan mm

\begin{tabular}{|c|c|c|c|c|c|}
\hline \multirow[t]{2}{*}{$\begin{array}{c}\text { Konsentrasi } \\
\text { Ekstrak Daun } \\
\text { Teh }\end{array}$} & \multicolumn{3}{|c|}{$\begin{array}{c}\text { Pengamatan Zona } \\
\text { Hambatan } \\
\text { Pertumbuhan Bakteri } \\
(\mathrm{mm})\end{array}$} & \multirow[t]{2}{*}{$\begin{array}{l}\text { Rata- rata zona } \\
\text { hambatan }(\mathrm{mm})\end{array}$} & \multirow[t]{2}{*}{$\begin{array}{l}\text { FI. Ed IV: Zona } \\
\text { Hambatan } \\
\text { sebagai } \\
\text { Antibakteri (mm) }\end{array}$} \\
\hline & I & II & III & & \\
\hline $2 \%$ & 12,5 & 12,3 & 12 & 12,3 & \\
\hline $3 \%$ & 13,8 & 14,3 & 14,1 & 14,1 & \\
\hline $4 \%$ & 15,2 & 14,6 & 14,9 & 14,9 & $14-16$ \\
\hline $5 \%$ & 15 & 15,4 & 15 & 15,1 & \\
\hline $6 \%$ & 15,7 & 15,7 & 16 & 15,8 & \\
\hline Etanol 96\% & 0 & 0 & 0 & 0 & \\
\hline
\end{tabular}

Penelitian ini menggunakan sampel ekstrak kental daun teh dengan tujuan untuk menguji efek antibakteri dalam menghambat pertumbuhan bakteri Escherichia coli dengan menggunakan metode difusi agar yaitu punch hole (lubang difusi). Menurut Farmakope Indonesia Edisi IV, zona hambatan antibakteri yang memuaskan adalah 14-16 mm. Dari data hasil pengamatan tabel 1 dapat dilihat bahwa konsentrasi ekstrak daun teh $2 \%$ belum dapat dikatakan sebagai antibakteri, tetapi sudah dapat menghambat pertumbuhan bakteri.

Ekstrak daun teh pada konsentrasi 3\%, 4\%, $5 \%$ dan $6 \%$ telah dapat dikatakan sebagai antibakteri. Konsentrasi ekstrak daun teh $3 \%$ merupakan konsentrasi hambat minimum karena rata-rata diameter zona hambat minimum pada konsentrasi tersebut adalah $14,1 \mathrm{~mm}$.

Dari hasil pengamatan juga terlihat bahwa perbandingan diameter zona hambat yang dihasilkan oleh ekstrak daun teh berbanding lurus dengan penambahan konsentrasi ekstrak daun teh. Semakin besar konsentrasi maka zona hambatan juga akan semakin besar karena konsentrasi yang lebih besar mengandung lebih banyak zat aktif antibakteri. Kontrol negatif yang digunakan dalam penelitian ini adalah etanol $96 \%$ ternyata tidak memberikan daya hambat terhadap pertumbuhan bakteri Escherichia coli atau tidak memiliki efek antibakteri.

\section{SIMPULAN DAN SARAN}

\section{Simpulan}

a. Ekstrak daun teh memiliki efek antibakteri terhadap pertumbuhan bakteri Escherichia coli pada konsentrasi di atas atau sama dengan $3 \%$.

b. Ekstrak daun teh pada masing-masing konsentrasi $2 \%, 3 \%, 4 \%, 5 \%$ dan $6 \%$ mempunyai daya hambat yaitu $12,3 \mathrm{~mm} ; 14,1 \mathrm{~mm} ; 14,9 \mathrm{~mm} ; 15,1$ $\mathrm{mm}$ dan $15,8 \mathrm{~mm}$. 
c. Tiap konsentrasi memberikan luas daerah hambat yang berbeda. Semakin besar konsentrasi maka zona hambatan juga akan semakin besar.

\section{Saran}

Disarankan kepada peneliti selanjutnya untuk:

a. Meneliti efek antibakteri ekstrak daun teh terhadap jenis bakteri lain.

b. Meneliti khasiat lain dari ekstrak daun teh.

\section{DAFTAR PUSTAKA}

Ajisaka. 2012. Teh Khasiatnya Dahsyat. Surabaya: Stomata

Dalimartha, S. 1999. Atlas Tumbuhan Obat Indonesia Jilid I. Jakarta: Trubus Agriwidya

Departemen Kesehatan RI. 1979. Farmakope Indonesia Edisi III. Jakarta

Edisi IV. Jakarta

Department of Food Science and Technology. 2010. Mendapatkan Khasiat Teh dari Pangan dan Kreasi Sendiri. [online]. Available at: <http://itp.fateta.ipb.ac.id/index.php?option=com_c ontenttask=view\&id=2Itemid=299> [Accessed 20 June 2014]

Heinrich, M., Joanne, B., Gibbons, S. 2009. Farmakognosi dan Fitoterapi. Penerjemah: Syarief, W.R. Jakarta: EGC
Pelczar, M.J, Jr. dan E.C.S. 1986. Dasar-Dasar Mikrobiologi Jilid 1. Penerjemah: Hadioetomo, R.S, dkk. Jakarta: Penerbit Universitas Indonesia

. 1988. Dasar-Dasar Mikrobiologi Jilid 2. Penerjemah: Hadioetomo, R.S, dkk. Jakarta: Penerbit Universitas Indonesia

Pratiwi, S.T. 2008. Mikrobiologi Farmasi. Jakarta: Penerbit Erlangga

Rossi, A. 2010. 1001 Teh: Dari Asal Usul, Tradisi, Khasiat Hingga Racikan Teh. Yogyakarta: Penerbit Andi

Setiawan, L. 2005. Prosedur Laboratorium Dasar untuk Laboratorium Klinis Edisi 2. Jakarta: Penerbit Buku Kedokteran EGC

Setyamidjaja, D. 2000. Teh: Budidaya dan Pengolahan Pasca Panen. Yogyakarta: Penerbit Kanisius

Syamsuhidayat, S.S \& Johnny, R.H. 1991. Inventaris Tanaman Obat. Departemen Kesehatan RI Badan Penelitian dan Pengembangan Kesehatan

The Merck Index. 2006. An Encyclopedia of Chemicals, Drugs and Biologicals $14^{\text {th }}$ ed. USA: Merck \& Co.,INC.

Trubus volume 10. 2012. Herbal Indonesia Berkhasiat: Bukti Ilmiah \& Cara Racik Edisi Revisi. Depok: PT Trubus Swadaya

Werner, D., Carol, T., Jane, M. 2010. Apa yang Anda Kerjakan Bila Tidak Ada Dokter. Yogyakarta: Penerbit Andi

Widyaningrum, H. 2011. Kitab Tanaman Obat Nusantara. Yogyakarta: Medpress. 